\title{
Autologous limbal transplantation in patients with unilateral corneal stem cell deficiency
}

Harminder S Dua, Augusto Azuara-Blanco

\begin{abstract}
Aim-To describe a surgical technique for autologous limbal stem cell transplantation and the outcome of a series of patients with unilateral stem cell deficiency.

Methods-A report of six consecutive patients who underwent autologous limbal stem cell transplantation is presented. The primary diagnosis included alkali burn $(n=3)$, conjunctival intraepithelial neoplasia (CIN) $(n=1)$, recurrent pterygium $(n=1)$, and contact lens induced keratopathy $(n=1)$. The autologous transplanted tissue consisted of peripheral cornea, limbus, and conjunctiva obtained from the contralateral eye. Three of the above patients underwent penetrating keratoplasty in association with autolimbal transplantation. A significant modification to established techniques was the close monitoring of conjunctival epithelial migration in the immediate postoperative period. If conjunctival epithelium threatened to migrate on to the corneal surface, it was mechanically removed at the slit lamp and prevented from crossing the limbus. This was required in three patients.
\end{abstract}

Results-The mean follow up was 18.8 months. The outcome was satisfactory in all cases: a stable corneal surface was restored and there was a substantial improvement in vision and symptoms. One patient had a primary failure of the corneal allograft associated with glaucoma, and 6 months later developed a retinal detachment. No complications were noted in the donor eye with the exception of one patient who developed filamentary keratitis along the edge of the donor site.

Conclusion-Autologous limbal transplantation with corneal, limbal, and conjunctival carriers was found to be useful for ocular surface reconstruction, over a mid-term follow up, in patients with unilateral stem cell deficiency. Close monitoring of the migration of conjunctival epithelium in the immediate postoperative period, and preventing it from crossing the limbus, ensured that the corneal surface was re-epithelialised exclusively from epithelial cells derived from the transplanted limbal tissue. This approach should improve the success of this procedure.

(Br f Ophthalmol 2000;84:273-278)
Clinical and laboratory evidence indicates that corneal stem cells are located at the limbus. ${ }^{1-5}$ Limbal deficiency, or loss of corneal stem cells, is associated with conjunctivalisation of the corneal surface, recurrent and persistent epithelial defects, chronic inflammation, scarring, and ulceration of the cornea. The management of these ocular surface disorders continues to pose a challenge. Early methods of reconstruction of the ocular surface included conjunctival transplantation and keratoepithelioplasty. Conjunctival transplantation was based on the theory of transdifferentiation of conjunctival epithelium into cornea-like epithelium..$^{6-8}$ However, we now know that conjunctival epithelial transdifferentiation (that is, a morphological, biochemical, and physiological transformation of conjunctival epithelium into corneal epithelium) does not occur, ${ }^{910}$ and conjunctival transplantation to reconstruct the corneal surface in patients with corneal stem cell deficiency has been abandoned. Keratoepithelioplasty was proposed by $\mathrm{Thoft}^{11}$ as another alternative to reconstruct the ocular surface in patients with corneal stem cell deficiency. In this technique lenticules of peripheral corneal epithelium with superficial stroma were grafted. Subsequently, the same author modified the technique to include limbal tissue, acknowledging the importance of stem cell transplantation in these conditions, for a successful long term outcome. The use of cultured limbal epithelium is, at present, still under investigation. ${ }^{12}$ Limbal transplantation, as proposed by Kenyon and Tseng, ${ }^{13}$ is probably the best current option for ocular surface reconstruction in patients with total corneal stem cell deficiency.

This report describes a modified surgical technique for autologous limbal transplantation and the outcome in a series of patients with unilateral corneal stem cell deficiency.

\section{Methods}

Six consecutive patients with unilateral corneal stem cell deficiency who underwent autologous limbal transplantation were included. Demographics and clinical characteristics are summarised in Table 1. Five patients had long standing symptoms and signs characteristic of chronic and diffuse corneal stem cell deficiency including decreased vision, pain, photophobia, discomfort, corneal vascularisation and scarring, chronic redness, and recurrent episodes of epithelial defects. One patient (case 6) had a recurrent pterygium with restriction of ocular motility. The pterygium had been excised four times over a period of 6 years. A conjunctival autotransplant was used to cover
Accepted for publication 25 October 1999 
Table 1 Demographics and clinical data of patients undergoing autologous limbal graft

\begin{tabular}{|c|c|c|c|c|c|c|c|c|c|}
\hline $\begin{array}{l}\text { Patient } \mathrm{No}, \\
\text { age (years), } \\
\text { sex }\end{array}$ & Eye & Primary diagnosis & Previous surgeries & $\begin{array}{l}\text { VA before } \\
A L T\end{array}$ & $\begin{array}{l}\text { Surgeries } \\
\text { associated }\end{array}$ & $\begin{array}{l}\text { Months of } \\
\text { follow up }\end{array}$ & $\begin{array}{l}\text { VA after } \\
A L T\end{array}$ & Complications & Success \\
\hline $1,39, \mathrm{~F}$ & $\mathrm{R}$ & $\mathrm{CIN}$ & $\begin{array}{l}\text { Excisional biopsy (alcohol, } \\
\text { cryotherapy) }\end{array}$ & $6 / 36$ & - & 19 & $6 / 9$ & $\begin{array}{l}\text { Reccurrence of CIN } \\
\text { (controlled with } \\
\text { MMC) }\end{array}$ & Yes \\
\hline $2,30, M$ & $\mathrm{R}$ & Chemical burn & - & $1 / 60$ & - & 31 & $6 / 36$ & - & Yes \\
\hline $3,79, M$ & $\mathrm{R}$ & $\begin{array}{l}\text { Aphakia, CL wear } \\
\text { multiple surgeries } \\
\text { corneal glueing }\end{array}$ & $\begin{array}{l}\text { FS, ECCE + AV, AC-IOL, } \\
\text { PK }(\times 2)\end{array}$ & $\mathrm{HM}$ & PK & 18 & $\mathrm{HM}^{\star}$ & $\begin{array}{l}\text { Glaucoma, PK } \\
\text { failure }\end{array}$ & $\mathrm{No}^{\star}$ \\
\hline $4,24, M$ & $\mathrm{~L}$ & Chemical burn & Mucosal graft & HM & PK & 16 & $6 / 36$ & - & Yes \\
\hline $5,58, \mathrm{~F}$ & $\mathrm{~L}$ & Chemical burn & - & $2 / 60$ & PK & 15 & $6 / 36$ & - & Yes \\
\hline $6,50, M$ & $\mathrm{R}$ & Recurrent pterygium & $\begin{array}{l}\text { Pterygium excision }(\times 4) \\
\text { autoconjunctival graft }(\times 1)\end{array}$ & $6 / 18$ & $\begin{array}{l}\text { Conjunctival } \\
\text { graft and } M M C\end{array}$ & 14 & $6 / 9$ & - & Yes \\
\hline
\end{tabular}

$\mathrm{VA}=$ visual acuity; ALT = auto-limbal transplantation; $\mathrm{CIN}=$ carcinoma in situ; $\mathrm{MMC}=$ mitomycin $\mathrm{C}$; CL = contact lens; FS = filtration surgery; ECCE = extracapsular cataract extraction; $\mathrm{AV}=$ anterior vitrectomy; $\mathrm{AC}-\mathrm{IOL},=$ anterior chamber intraocular lens implantation; $\mathrm{PK}=$ penetrating keratoplasty; HM = hand movements.

*VA loss and failure after retinal detachment.

the sclera at the time of the fourth excision, performed a year before presentation. Despite this the pterygium had recurred and encroached on the visual axis causing reduced vision and diplopia.

The surgical technique was similar in all cases. The donor tissue consisted of corneallimbal-conjunctival explant(s) that were harvested from the contralateral normal eye, except in case 6 , where it was harvested from the superior limbus of the same eye. In cases 1-4, two explants, corresponding to 2 clock hours (11-1 o'clock and 5-7 o'clock) and consisting of $2 \mathrm{~mm}$ of peripheral cornea, limbus, and $3 \mathrm{~mm}$ of bulbar conjunctiva, were harvested. In case 5, only one explant from the superior limbus of the contralateral eye and in case 6 only one explant, corresponding in circumferential length to 3 clock hours, were harvested. A front running double edged calibrated diamond knife was set to $150 \mu \mathrm{m}$. The knife was used to make a circumferential corneal incision, parallel to the limbus, and two radial incisions, extending from either end of the circumferential incision to the limbus. An angled bevelled blade was used to (lamellar) dissect the $150 \mu \mathrm{m}$ of corneal tissue and the dissection was extended to include the limbal tissue and emerge beyond the limbus, under the conjunctiva. Three millimetres of conjunctiva, attached to the corneal and limbal explant along the limbal border, were then excised.

The recipient eye was prepared by incising the conjunctiva, at the limbus, adjacent to the area with the most severe corneal surface abnormalities, or at the superior and inferior
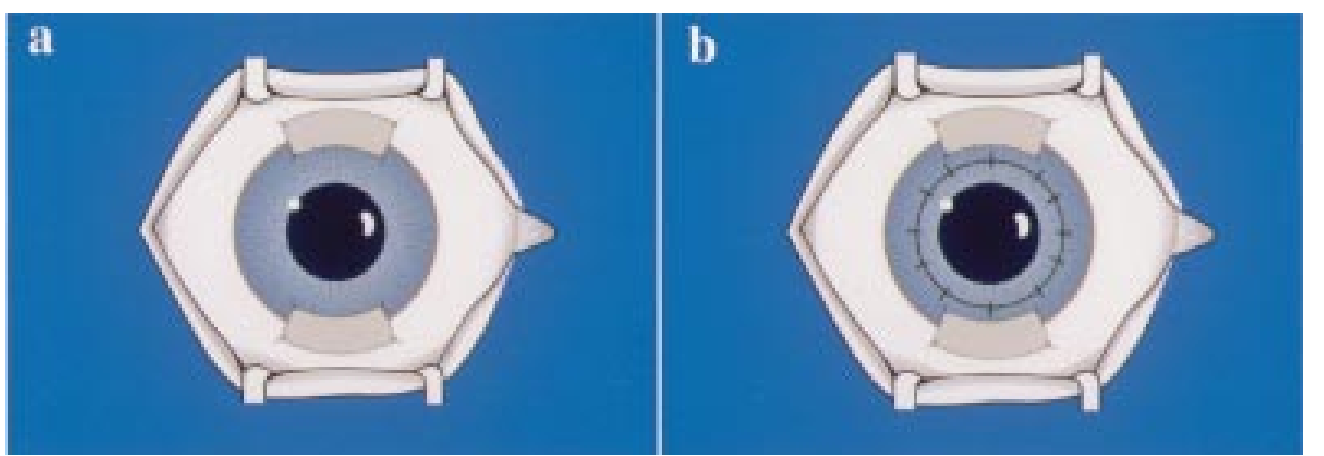

Figure 1 (a) Diagram illustrating the placement of auto-limbal explants at the 6 and 12 o'clock positions of recipient eye. (b) Auto-limbal transplant with corneal graft. The graft is usually $7 \mathrm{~mm}$ in size as the peripheral $2 \mathrm{~mm}$, both above and below, is covered by the explants. limbus. The abnormal corneal epithelium and the superficial fibrovascular scar tissue were stripped off by blunt dissection. The calibrated diamond knife was set to $100 \mu \mathrm{m}$ (an allowance of $50 \mu \mathrm{m}$ was made for the lack of epithelium) and a bed, corresponding in dimensions to the donor explants, was fashioned at the recipient site(s). The donor tissue was then sutured onto the recipient eye with two interrupted 10-0 nylon sutures at the corneal margin and two along the scleral edge of the explant (Fig 1a). The conjunctiva of the recipient eye was then approximated to the donor conjunctiva with interrupted 8-0 Vicryl sutures, taking a bite into episclera. When a penetrating keratoplasty was also required, this was performed after the limbal explants were first sutured into place (Fig 1b).

Two patients (cases 3 and 5) underwent penetrating keratoplasty (PK) at the time of limbal transplantation, and case 4 underwent PK 4 months after the original procedure. In case 6 , mitomycin C $(0.04 \%, 1$ minute) was applied intraoperatively with a Weck-cel sponge to the subconjunctival tissue after excision of the recurrent pterygium and fibrous tissue. This was irrigated thoroughly before suturing the limbal explant.

Postoperative treatment consisted of preservative-free topical chloramphenicol and prednisolone $0.5 \%$ eye drops, four times daily for the first 2 weeks. Steroids were then tapered rapidly. Autologous serum drops were used in the immediate postoperative period, as previartificial tears were also used. ously described. ${ }^{14}$ Frequent preservative-free 

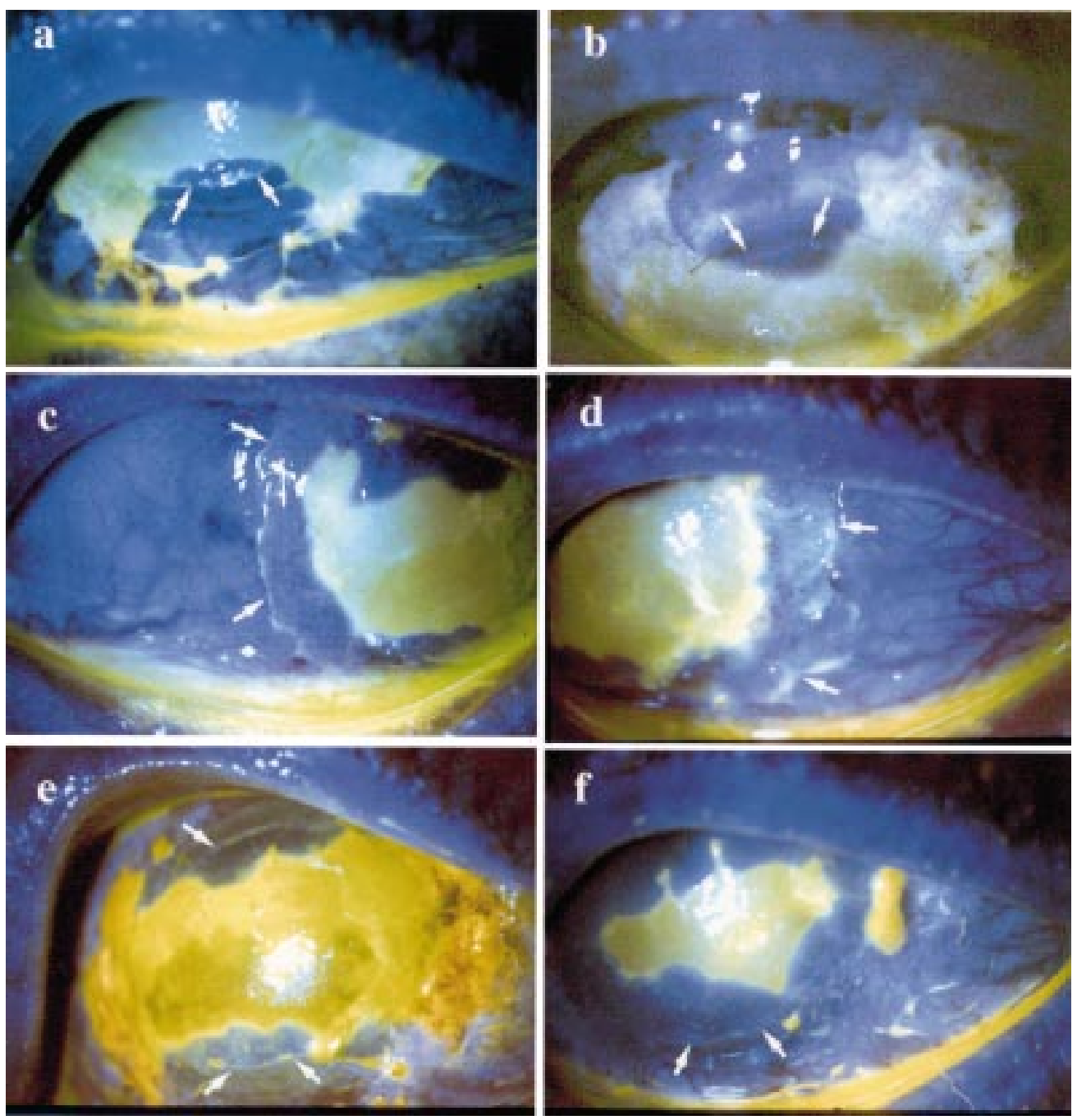

Figure 2 Fluorescein stained ocular surface photographs of recipient eye that had undergone auto-limbal transplantation. On day 2 following surgery, donor epithelial cells can be seen migrating on to the recipient surface from the explants placed at the 6 o'clock (a) and 12 o'clock (b) positions. Arrows indicate the anterior edge of the explants. On day 4 following surgery, host conjunctival epithelial cells can be seen migrating from the edge (arrows) of the recessed conjunctiva on both the temporal (c) and nasal (d) sides. The advancing conjunctival epithelial sheets were mechanically debrided with a surgical blade (e), leaving behind the limbal explant derived expanding corneal epithelial cells (arrows). (f) The circumferentially migrating limbal explant derived corneal epithelial cells have met temporally and nasally. The large corneal epithelial defect healed with corneal cells and the small nasal conjunctival defect healed with conjunctival cells. Healing was complete by day 8.

All patients were followed daily or twice daily until corneal epithelialisation was complete. If conjunctival epithelium was seen to progress towards the limbus or encroach on to the cornea, it was mechanically debrided under topical anaesthesia, at the slit lamp as previously described, ${ }^{10}$ to ensure that corneal reepithelialisation occurred with corneal epithelial cells derived from the transplanted explants. This was required in three patients (Fig 2a-f).

\section{Results}

In this series of patients median follow up time was 18.8 months (Table 1). No intraoperative complications occurred. Postoperatively, the limbal grafts started epithelial outgrowths within the first 2 days (Fig 2a, b) and the whole corneal surface was completely epithelialised within 2 weeks, in all cases. There was no infection, limbal graft failure, or slippage of tissue. The epithelium was stable, without recurrence of epithelial defects, transparent, and smooth. There was no corneal neovascularisation. Improvement of vision and symptoms after surgery was substantial in all cases (see Table 1 and Fig 3a-e). Case 3 had primary failure of the corneal allograft and glaucoma. Four weeks later he underwent repeat PK and diode laser cyclophotocoagulation was applied to the areas not covered by the limbal tissue. The outcome was satisfactory until 6 months later, when a retinal detachment was noted. Although the corneal surface remained healthy during follow up, his visual function deteriorated to hand movements.

In the donor eyes there were no intraoperative complications, refractive changes, chronic inflammation, persistent epithelial defects, or corneal neovascularisation. One of the patients (case 3) developed filamentary keratitis in the donor eye, which was controlled with intense topical lubrication.

Case 1, who had conjunctival intraepithelial neoplasia, had a recurrence of the lesion 


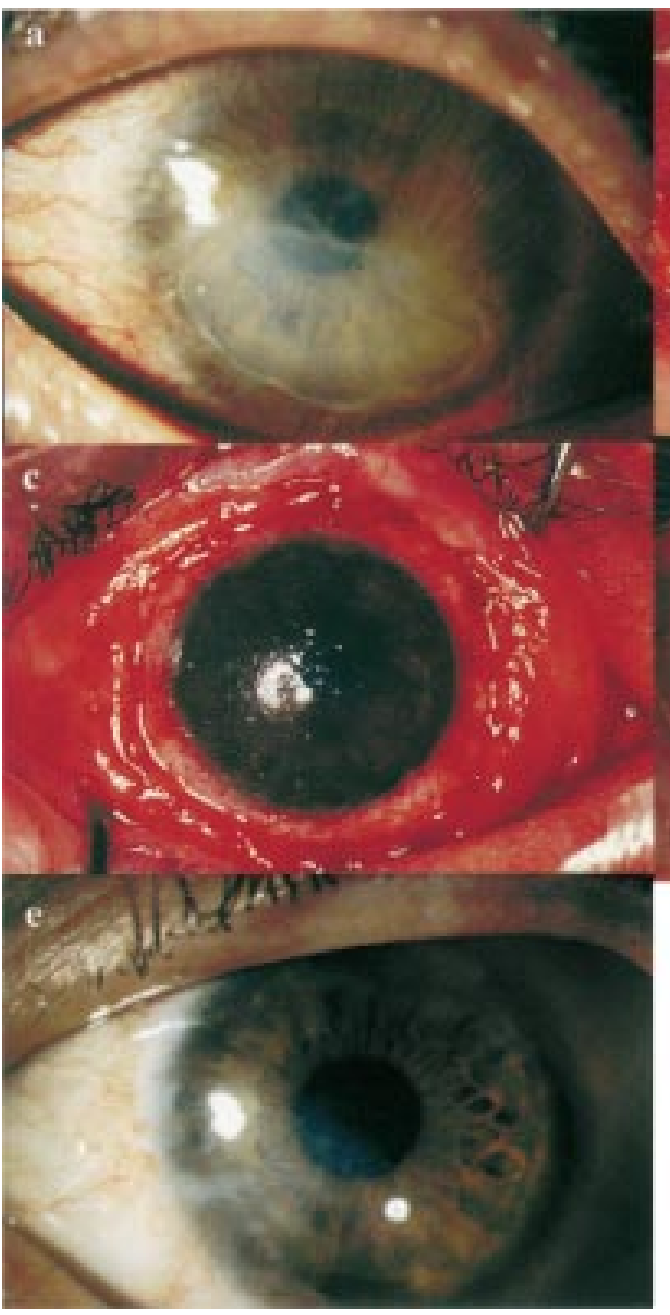

following auto-limbal transplantation. This had extended on to the cornea for approximately $4 \mathrm{~mm}$ at the time it was first seen. She was treated with mitomycin $\mathrm{C}$ drops and the abnormal epithelium disappeared, leaving the eye symptom free with a visual acuity of $6 / 9$. Topical mitomycin $\mathrm{C}$ therapy did not affect the viability of the limbal grafts during the 6 month follow up period after completion of treatment.

Histological examination (available for two cases) of the fibrovascular membrane with overlying epithelium, excised from the corneal surface at the time of surgery, showed numerous intraepithelial goblet cells and basal intraepithelial lymphocytes. Preoperative impression cytology was performed for only one patient and this too showed multiple goblet cells. Pathological examination thus provided further evidence of the conjunctival origin of the "corneal epithelium".

\section{Discussion}

A variety of techniques of limbal transplantation have been reported. All these procedures provide a new source of epithelium for a diseased ocular surface and the removal of the host's altered corneal epithelium and pannus. From the donor tissue, transient amplifying cells are generated which migrate onto the denuded corneal surface of the host. The donor tissue can be obtained from the fellow

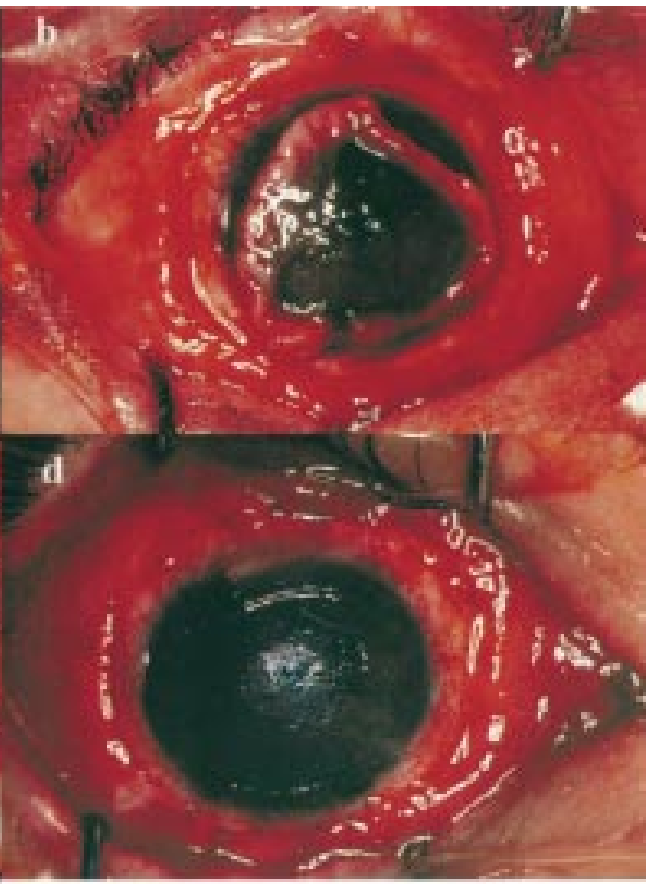

Figure 3 (a) Preoperative photograph of the eye of a patient with alkali burn and a large persistent corneal epithelial defect. (b) Intraoperative photograph showing recessed conjunctiva and removal of fibrovascular tissue from the corneal surface. (c) After removal of

fibrovascular tissue, the underlying corneal stroma is found to be clear and transparent. (d) Intraoperative photograph showing auto-limbal explants sutured in place at the 6 and 12 o'clock positions. (e) Postoperative photograph after corneal epithelial healing was complete (taken 1 month after surgery).

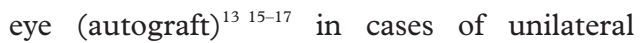
disease. Cadaveric whole globe or corneoscleral rim or a living relative (allograft) ${ }^{14}$ 18-22 can be used when both eyes are affected. Limbal transplantation procedures also vary depending on the carrier tissue used for the transfer of the limbal stem cells. Carrier tissue is needed in limbal transplantation because it is not possible to transfer limbal stem cells alone. Either conjunctiva (conjunctival limbal graft) ${ }^{13}$ or corneal/limbal stroma (keratolimbal graft) have been used as carrier tissue for limbal stem cells.

This study describes the outcome of six patients who underwent a modified surgical technique of autologous limbal transplantation for a variety of ocular surface diseases. Superficial corneal stroma, perilimbal sclera, and conjunctiva were used as carriers for limbal cells and providers of an adequate microenvironment for their survival and replication. All cases achieved rapid surface healing with restoration of a smooth, stable, and optically improved surface, resulting in improved visual acuity. A key factor contributing to the success of this study is the early recognition of conjunctival epithelial migration towards the limbus and the prevention of such migration onto the cornea. To achieve this end it is imperative to monitor closely all patients following transplantation, until corneal re- 
epithelisation, or at least limbal reepithelisation, with the auto-limbal transplant derived corneal epithelial cells, is complete. Failure to recognise this would result in a mosaic of corneal and conjunctival cells populating the corneal surface and apparent failure of the procedure. The underlying principles of this approach have been elaborated on in previous publications. ${ }^{102324}$ This is the first study where this approach has been successfully applied to the management of patients undergoing auto-limbal transplantation.

The donor eyes healed rapidly without complication with the exception of one donor eye, which developed filamentary keratitis, and was controlled with topical lubricants. Jenkins et $a l^{17}$ observed that one of five donor eyes developed epitheliopathy after autologous limbal transplantation for ocular surface disease from chronic contact lens wear. It is likely that the donor eye that developed epitheliopathy was not normal, as it was also exposed to chronic contact lens wear. To avoid such complications it is important to obtain limbal tissue from donor eyes with healthy epithelial surface. Microperforation of the donor eye has also been reported..$^{25}$ With our technique (superficial stromal dissection of the donor tissue, facilitated by a calibrated diamond knife) microperforation of the donor eye is unlikely to occur. We did not observe this complication in any of our patients.

The most frequent diagnosis was chemical burn $(n=3)$. These patients had long standing poor vision and were not manageable with keratoplasty alone as lamellar or penetrating keratoplasty provides only a temporary replacement of the host's corneal epithelium and does not permanently reconstitute the limbal function. One patient had retinal detachment and poor visual outcome. It is unlikely, though, that this complication was associated with limbal transplantation.

Resection of squamous cell carcinoma with extensive limbal and corneal involvement was associated with alcohol application to the epithelium and, after resection, with double freeze thaw cryotherapy to the affected area to prevent recurrences. With this treatment ocular surface morbidity resulting from stem cell destruction is very likely to occur. Autologous limbal transplantation to restore the ocular surface after conjunctival squamous cell carcinoma resection has been reported by Copeland and $\operatorname{Char}^{26}(\mathrm{n}=2)$ and by Tan et $a l^{27}$ (one case). In the latter case a mild recurrence of abnormal epithelium was noted 10 months after surgery. In this study there was a recurrence of the epithelial carcinoma, which was successfully treated with mitomycin $\mathrm{C}$ eye drops without compromising the normal corneal epithelium.

Localised corneal stem cell dysfunction as loss of limbal barrier against conjunctival invasion has been proposed as a pathogenic factor in pterygium growth and recurrence. Multiple surgical approaches have been used to treat recurrent pterygia as simple excision results in severe fibrous tissue regrowth. To treat this disorder both suppression of subconjunctival fibrosis and reconstruction of the limbal barrier are important. Intraoperative or postoperative antifibrotic agents have been used to reduce the probability of recurrence of pterygium. ${ }^{28}$ Autologous limbal transplantation ${ }^{30}$ and amniotic membrane transplantation (AMT) ${ }^{31}$ have been proposed as a valid option in recurrent cases. In this study, pterygium excision supplemented with auto-limbal transplantation (without AMT) and mitomycin C application appeared to be successful after mid-term follow up.

In conclusion, the use of autologous limbal transplantation with corneal, scleral, and conjunctival carriers was useful for ocular surface reconstruction in patients with unilateral stem cell deficiency. The importance of recognising and preventing the migration of conjunctival epithelium on to the corneal surface, as highlighted by this study, will significantly improve the outcome of auto-limbal transplantation.

Dr Azuara-Blanco was the Vision Express fellow in cornea and contact lenses (July 1997-December 1998).

We are grateful to Miss April Powell-Richards for her technical assistance with the manuscript, especially with the colour $\mathrm{cal}$ assistance with the manuscript, especially with the colour
photographs. Augusto Azuara-Blanco was supported by Vision photographs. Augusto
Express UK Limited.

1 Kinoshita S, Kiorpes T, Friend J, et al. Limbal epithelium in ocular surface wound healing. Invest Ophthalmol Vis Sci ocular surface

2 Chen JJY, Tseng SCG. Corneal epithelial wound healing in partial limbal deficiency. Invest Ophthalmol Vis Sci 1990;31 1301-14.

3 Chen JJY, Tseng SCG. Abnormal corneal epithelial wound healing in partial thickness removal of limbal epithelium. Invest Ophthalmol Vis Sci 1991;32:2219-33.

4 Kruse FE. Stem cells and corneal epithelial regeneration. Eye 1994;8:170-83.

5 Huang AJW, Tseng SCG. Corneal epithelial wound healing in the absence of limbal epithelium. Invest Ophthalmol Vis Sci 1991;32:96-105.

6 Thoft RA. Conjunctival transplantation. Arch Ophthalmol 1977;95:1425-7.

7 Vastine DW, Stewart WB, Schwab IR. Reconstruction of the periocular mucous membrane by autologus conjunctival periocular mucous membrane by autologus conjun

8 Herman WK, Doughman DJ, Lindstrom RL. Conjunctival autograft transplantation for unilateral ocular surface autograft transplantation for unilateral
diseases. Ophthalmology 1983;90:1121-6.

9 Harris TM, Berry ER, Pakurar AS, et al. Biochemical transformation of bulbar conjunctiva into corneal epithelium: an electrophoretic analysis. Exp Eye Res 1985;41:597-605

10 Dua HS. The conjunctiva in corneal epithelial wound healing. Brf Ophthalmol 1988;82:1407-11.

11 Thoft RA. Keratoepithelioplasty. Am $\mathcal{F}$ Ophthalmol 1984;97: $1-6$.

12 Lindberg K, Brown ME, Chaves HV, et al. In vitro propagation of human ocular surface epithelial cells for transplantation. Invest Ophthalmol Vis Sci 1993;34:2672-9.

13 Kenyon KR, Tseng SCG. Limbal autograft transplantation for ocular surface disorders. Ophthalmology 1989;96:709-

14 Dua HS, Azuara-Blanco A. Allo-limbal transplantation in patients with corneal stem-cell deficiency. Brf Ophthalmol patients with cor

15 Clinch TE, Goins KM, Cobo LM. Treatment of contact lens-related ocular surface disorders with autologous conjunctival transplantation. Ophthalmology 1992;99:6348 .

16 Mashima Y, Yamada M, Yamada H, et al. Limbal autograft transplantations for chronic ocular surface failures. $\mathcal{F} p n \mathcal{F}$ Clin Ophthalmol 1993;47:607-10.

17 Jenkins C, Tuft S, Liu C, et al. Limbal transplantation in the management of chronic contact-lens associated epitheliopathy. Eye 1993;7:629-33.

18 Turgeon PW, Neuheim RC, Roat MI, et al. Indications for keratoepithelioplasty. Arch Ophthalmol 1990;108:233-6.

19 Pfister R. Corneal stem cell disease: concepts, categorization, and treatment by auto- and homotransplantation of limbal stem cells. CLAO ₹ 1994;20:64-72.

20 Tsai RJF, Tseng SCG. Human allograft limbal transplantation for corneal surface reconstruction. Cornea 1994;13: 389-400.

21 Kenyon KR, Rapoza PA. Limbal allograft transplantation for ocular surface disorders. Ophthalmology 1995;102 (suppl):101-2. 
22 Tsubota K, Toda I, Saito H, et al. Reconstruction of the corneal epithelium by limbal allograft transplantation for severe ocular surface disorders. Ophthalmology 1995;102:1486-96.

23 Dua HS, Forrester JV. The corneoscleral limbus in corneal epithelial wound healing. Am f Ophthalmol 1990;110:646-56. 24 Dua HS, Gomes JA, Singh A. Corneal epithelial wound healing. Br f Ophthalmol 1994;78:401-8.

25 Morgan S, Murray A. Limbal auto-transplantation in the acute and chronic phases of severe chemical injuries. Eye 1996;10:349-54.

26 Copeland RA, Char DH. Limbal autograft reconstruction after conjunctival squamous cell carcinoma. Am $\mathcal{F}$ Ophthalmol 1990;110:412-15.

27 Tan DTH, Ficker LA, Buckley RJ. Limbal transplantation. Ophthalmology 1996;103:29-36.
28 Hayasaka S, Noda S, Yamamoto Y, et al. Postoperative instillation of low-dose mitomycin-C in the treatment of primary pterygium. Am $F$ Ophthalmol 1988,106:715-

9 Mastropasqua L, Carpineto P, Ciancaglini M, et al. Long erm results of intraoperative mitomycin $\mathrm{C}$ in the treatment of recurrent pterygium. $\mathrm{Br} f$ Ophthalmol 1996;80:288-91.

30 Shimazaki J, Shinozaki N, Tsubota K. Transplantation of amniotic membrane and limbal autograft for patients with recurrent pterygium associated with symblepharon. $\mathrm{Br} \mathcal{F}$ Ophthalmol 1998;82:235-40

31 Prabhasawat P, Tseng SCG. Impression cytology study of epithelial phenotype of ocular surface reconstructed by preserved amniotic membrane. Arch Ophthalmol 1997;115: 1360-7. 